\title{
Los lugares espacian el espacio ${ }^{1}$ Places Spacing Space
}

\author{
Aldo Hidalgo Hermosilla \\ Universidad de Santiago de Chile \\ buffone_hi@hotmail.com
}

\section{Resumen:}

En agosto de 1951, en la ciudad de Darmstadt, el filósofo Martin Heidegger dictó la conferencia "Construir, Habitar, Pensar". De esa reflexión, la teoría de la arquitectura se ha nutrido de substanciales argumentos que le han permitido repensar el espacio no ya en cuanto matriz geométrica del proyecto físico-técnico, motivo central de la estética moderna, sino como algo construido y vivido, es decir, como lugar. En este ensayo, siguiendo las pautas de Heidegger, se bosqueja la idea de que si se examina el famoso texto, conjuntamente con la cabaña que el filósofo ocupaba en la localidad de Todtnauberg, en Alemania, se atisba una noción vinculada a la existencia: el espacio-lugar. Y esta noción, a su vez, nos remite a la pregunta por el espacio en cuanto tal.

Palabras clave: espacio, existencial, lugar, cabaña, paseos.

\section{Abstract:}

In August 1951, in the city of Darmstadt, philosopher Martin Heidegger gave the lecture "Building Dwelling Thinking". From that reflection, architectural theory has been nurtured with substantial arguments that allowed rethinking space; not as a geometric matrix for the physical-technical project, centerpiece of modernist aesthetics, but as something built and lived; this is, as a place. In this essay, following the guidelines of Heidegger, we outline the idea that if the famous text is examined together with the hut that the philosopher occupied in the town of Todtnauberg, in Germany, we may glimpse a notion linked to the existence: the one of space-place. And, this notion, in turn, leads us to the question of space as such.

Keywords: Space, Existence, Place, Hut, Walks.

1 Este texto, revisado y reescrito en parte, corresponde al capítulo 3 de la primera parte de la tesis doctoral: La producción de vacío: Argumentos heideggerianos para repensar el espacio en la arquitectura, presentada en diciembre del 2011 en la Universidad de Chile. 


\title{
Introducción
}

\author{
Porque más allá del espacio, parece, \\ no hay nada a lo que el espacio se pueda reducir. \\ Ante él no hay ningún desviarse hacia otra cosa. \\ Lo propio del espacio tiene que mostrarse desde sí mismo. \\ ¿Pero se deja aún decir lo suyo propio? \\ M. Heidegger. El arte y el espacio.
}

Una de las reflexiones más originales respecto de una concepción existencial del espacio la hallamos en el libro Ser y Tiempo del filósofo alemán Martín Heidegger, publicado en 1927. Allí, en el capítulo tercero, parte c, parágrafos 22, 23 y 24 encontramos el análisis de los atributos principales de esa noción espacial que se opone a la noción tradicional y metafísica más conocida. La tentativa del filósofo es la de abrir un camino de comprensión más allá de la lógica cartesiana y de la determinación física, así como del a priori kantiano respecto de la exterioridad del espacio. La analítica desplegada en este libro está regida por la pregunta acerca de la existencia del dasein, lo que equivale a preguntar por la espacialidad del ser humano que se desenvuelve en la cotidianidad. Deriva de esta propuesta, que luego será ampliada y profundizada en otros escritos del filósofo, la idea de que dicha espacialidad se constituye en un "habitar junto a las cosas" (Safranski 194). Entre los numerosos textos que siguen esta indicación de la opera prima, está aquel que Heidegger leyó en la conferencia "Construir, Habitar, Pensar" (Bauen, Wohnen, Denken) en Darmstadt en 1951. De su novedad por el habla, por el cuidado analítico con que trata los actos cotidianos y, por qué no, por el lenguaje poético usado cuando refiere a la humilde construcción de una cabaña, se nutrirá la reflexión arquitectónica para incorporar y discutir el concepto central del discurso heideggeriano: el espacio ligado a la existencia.

Lo que se examinará a continuación refiere a algunas de las indicaciones del texto del Coloquio, en el que Heidegger analiza etimológicamente la significación y los alcances de los tres términos implicados en el título de la comunicación. De su análisis, resulta que el habitar se instaura como condición de posibilidad del construir. Para el filósofo, en efecto, el construir está precedido por una estructura fundamental de relación del hombre con el mundo -el habitar originario-, entendido este como la apertura que traza y resguarda las prácticas de sentido en las cuales se instituye la existencia humana en su relación con las cosas, los útiles y las obras. En este contexto, Heidegger hará la significativa diferencia entre lugar y espacio, caracterizando los lugares como aquellas presencias, cosas o construcciones, que se revelan como un modo de acceso a la relación entre hombre y espacio. Y es esta relación la que se debe tomar como referencia fundamental y antecedente esencial en la arquitectura para la configuración espacial. Así, tanto las cosas como las construcciones emergerían como lugares portadores de la promesa de un habitar, y, por tanto, la tarea de la arquitectura, la construcción diría Heidegger, sería darle forma en tanto tales. 
De esta exposición, y del impulso por indagar los alcances de este texto en la arquitectura, hemos imaginado la hipótesis de que la experiencia de habitar la cabaña en Todtnauberg le ha permitido a Heidegger identificar en su construcción la manifestación de un lugar. Y, el carácter de este, habitual y cotidiano, que lo distingue del sentido más abstracto de la concepción moderna, sugiere el despliegue de la noción de espacio-lugar como vía de acceso a la relación con la existencia. Más aun, sus paseos (Spaziergang) por el entorno de la cabaña y sus recorridos por los senderos de la Selva Negra (Schwarzwald) suscitan luego la pregunta por lo propio del espacio: la espacialidad.

\section{Texto y arquitectos}

Con ocasión del encuentro denominado originalmente "El hombre y el espacio" ("Mensch und Raum"), que luego será conocido como "El Coloquio de Darmstadt", se congregó un grupo de intelectuales, filósofos y arquitectos para escuchar la lectura del significativo escrito "Construir, habitar, pensar" de Heidegger. Texto que luego será publicado en las actas del evento, para después ser reimpreso junto a otros trabajos del filósofo en el libro Vorträge und Aufsätze (Conferencias y artículos), en 1954.

Los arquitectos presentes en la audiencia constituían un grupo protagonista de la reconstrucción en la Alemania de posguerra. En su libro Heidegger for architects, el arquitecto inglés Adam Sharr nos dice que quien tuvo a su cargo el encuentro fue Otto Bartning, a la sazón, director de la escuela de arquitectura de Weimar. Con anterioridad, Bartning junto a Walter Gropius, habían propuesto y desarrollado los programas pedagógicos del Bauhaus. Escuela que entre sus objetivos estaba aquel de reunir arte y técnica. También estuvieron presentes Pablo Bonatz, diseñador de la Estación de Stuttgart; Richard Riemerschmid, miembro importante del movimiento Jugendstil y Hans Scharoun, arquitecto del notable edificio de la Filarmónica de Berlín y de la Biblioteca Estatal de la misma ciudad. Sharr menciona también la presencia del sociólogo Alfred Weber, la del filósofo Hans-Georg Gadamer, discípulo de Heidegger, y la del célebre José Ortega y Gasset; este último, dejó un testimonio del encuentro en un ensayo titulado "En torno al Coloquio de Darmstadt" -aparecido en el libro Pasado y porvenir para el hombre actual-. En él, Ortega cuestiona el análisis etimológico al que recurre Heidegger en su conferencia. En especial, discute el supuesto origen común de las palabras habitar y construir, así como de la prioridad signada por el alemán del habitar sobre el construir.

Con el fin de mostrar más expresivamente la atmósfera generada por la acción de la reconstrucción y el impacto de la conferencia en los arquitectos alemanes, citaremos un pasaje del testimonio de Ortega. Escribe el filósofo:

Como es sabido, el coloquio versaba sobre arquitectura, y acudieron allí casi todos los grandes arquitectos alemanes -los viejos y los jóvenes- . Era conmovedor presenciar el brío, el afán, el trabajo con que aquellos hombres que viven sumergidos entre ruinas hablaban de su posible actuación. Dijérase que las ruinas han sido para ellos algo así 
como una inyección de hormonas que han disparado en su organismo un frenético deseo de construir. No creo que escenas de entusiasmo -individual y colectivo- como aquellas, puedan hoy presenciarse en ningún otro país de Occidente. Lo que allí vi y oí me inspiraba la intención de escribir un ensayo con este título: "La ruina como afrodisíaco". He ahí pues, una típica reacción de un pueblo joven frente a una catástrofe (Ortega y Gasset 32).

El texto de Heidegger, hemos dicho, ha tenido gran repercusión entre los arquitectos, lo mismo entre críticos e historiadores del siglo XX. Lo que en general parece relevarse en él, es una cierta visión ligada al mundo cotidiano, aunque con atisbos míticos, religiosos o naturalistas sobre el origen de los conceptos de habitar y construir. El poblado en la boscosa montaña y la pequeña cabaña mencionada por Heidegger, confirman esta aproximación a lo familiar y conocido. El corolario de este enfoque ha significado volver la mirada hacia prácticas regionales ancestrales y a las tradiciones locales respectivas. Entre los efectos más evidentes de la irradiación del texto en la teoría y la crítica arquitectónica, está la revalorización del trabajo artesanal en oposición a los procesos industriales, así como la vuelta a prácticas constructivas locales o tradicionales. Como consecuencia de ello, la acción arquitectónica de las décadas del ochenta y noventa -del siglo pasado- en culturas tan diversas como son la portuguesa, italiana, suiza o japonesa, estuvieron dirigidas por la voluntad de destacar los valores de la propia cultura por sobre aquellos de la arquitectura internacional o del International Style, como se llamó a la arquitectura nacida en la década del veinte. Confirma este hecho el debate posterior, según el cual a diversos autores les ha despertado nuevas motivaciones. En otro de sus libros, Adam Sharr comenta algunas de estas motivaciones:

[...] un reconocimiento de un espacio medido emocionalmente frente al medido matemáticamente; una visión mítica del construir y del habitar del pasado, en otros tiempos unificados como una única actividad, pero ahora disgregados por procedimientos profesionales y procesos tecnológicos; un deseo de orden temporal y físico significativo; una sensibilidad hacia las dimensiones de presencia y ausencia; y una interacción mutua de mente, cuerpo y lugar (Sharr, Heidegger's Hut 13).

Adam Sharr también menciona a los críticos e historiadores que se han identificado mayormente con las temáticas heideggerianas. Entre ellos están: el arquitecto noruego Christian Norberg-Schulz, el inglés Kenneth Frampton y el español Alberto Pérez-Gómez. También observa la influencia de los escritos heideggerianos en las obras de los arquitectos Hans Scharoun, Christopher Alexander, y entre los más contemporáneos, en las de Steven Holl, Juhani Pallasmaa y Peter Zumthor.

Un hecho que habla de la afición de un arquitecto por el texto lo relata H. G. Petzet en su libro Encuentros y diálogos con Heidegger 1929-1976. Destaca este autor y amigo del filósofo, la inclinación de la señora Heidegger por la construcción, lo que habría motivado el interés de su esposo por la arquitectura como arte. La anécdota que cuenta Petzet 
demuestra la satisfacción del filósofo al enterarse que el magnífico arquitecto moderno Alvar Aalto mantenía en su escritorio un ejemplar de "Construir, habitar, pensar". Cuando Heidegger supo de esta noticia, se apresuró alegremente a solicitar a Petzet que, en su próximo viaje a Finlandia, le llevara sus saludos al arquitecto. Lamentablemente, fue una misión que Petzet no pudo cumplir por el fallecimiento de Aalto (Petzet 244).

Ahora bien, si se analiza la poética de estos arquitectos, se obtiene un amplio rango de interpretaciones sobre el habitar, de la experiencia del espacio y de su concepción teórica. Pero, aunque en los conceptos de fondo leemos una adhesión al pensamiento heideggeriano, se tiene la impresión que la visión fenomenológica de Heidegger solo ha resultado ser un puente hacia otras fenomenologías de mayor impacto o actualidad. Como aquella de Maurice Merleau-Ponty, quien con su Fenomenología de la percepción, encontró terreno fértil en una disciplina, como la arquitectura, que se aboca a comprender la relación espacial entre hombre, cosas y mundo. En cualquier caso, el elemento común es la persistencia de estas arquitecturas por el cuidado del espacio vivido y por su concretización material, justamente como ocurre en el caso de Alvar Aalto. Por ende, las preguntas surgen ahora con respecto al significado de esas operaciones en la ciudad, en el barrio y la calle. Que sean diversos los puntos de vistas sobre la fenomenología, no significa que no se busque en todo ellos, eludir la determinación físico-técnica, como factor dominante en el proyecto de arquitectura.

Alberto Pérez-Gómez, en la introducción de Entrelazamientos, libro que trata sobre la obra del arquitecto norteamericano Steven Holl, subraya la importancia que ha cobrado en la actualidad el pensamiento de M. Merleau-Ponty, aunque reconociendo la influencia de los textos heideggerianos en la arquitectura. Al leer el texto, pese a que se refiere al pensador francés, nos parece escuchar las palabras y las ideas ya vertidas con anterioridad por el filósofo alemán. Escribe Holl:

Creer que los significados son simples asociaciones mentales, que el espacio está "ahí fuera" y que es un elemento meramente cuantitativo (que puede ser descrito con coordenadas tridimensionales), o que las imágenes descontextualizadas (en el ciberespacio) son reales, ha puesto en crisis la profesión arquitectónica de tal modo que el punto de vista de Merleau-Ponty resulta crucial y oportuno. La arquitectura ha de abordar este desafío con espíritu crítico, intentando recuperar el misterio de lo ordinario y poniendo de manifiesto la elocuente heterogeneidad de lo profundo (9, el énfasis es nuestro).

Más recientemente, como en el caso del finlandés Juhani Pallasmaa o del suizo Peter Zumthor, los trabajos teóricos y las realizaciones materiales buscan como objetivo teórico primordial poner en crisis el paradigma de la visión que ha dominado la arquitectura moderna. Privilegian, en cambio, la manifestación de las relaciones entre cuerpo y ambiente. Estas últimas experiencias han abierto un renovado interés por el espacio, al ser comprendido como aire, medio o atmósfera. Tal es el paradigma de la fenomenología de las atmósferas. 


\section{La faena del habitar}

La afirmación más rotunda que hace Heidegger, a través del análisis etimológico de los términos construir, habitar y pensar, es que el habitar antecede el construir. Para él, el acto de construir está precedido por la estructura fundamental de relación del hombre con el mundo -el habitar originario-, entendido este como apertura que traza las prácticas de sentido en la cual se instituye la existencia del hombre en su relación con las cosas. El habitar preexiste, pues el hombre ya "habita en la tierra, entre los mortales, frente al cielo y hacia los dioses" (Heidegger, "Construir, habitar, pensar" 144). El construir es un medio para habitar en tanto cuidado para hacer que el habitar sea.

Puestos en el contexto en el que esta conferencia surge, esa primera afirmación revela el interés de Heidegger por contraponer al mero utilitarismo, resultante de la acción de la reconstrucción de las ciudades alemanas, una reflexión sobre el habitar auténtico que superara la solución al mero alojamiento, como se estaba dando en esos momentos. Para dar extensión a este pensamiento, Heidegger, tal como ya lo había realizado en Ser $y$ Tiempo, también en el texto del Coloquio analiza etimológicamente las palabras que forman el título de su conferencia, reforzando su concepto de que la constitución del ser de una cosa, su sentido, está en el origen en cuanto palabra.

En "Construir, habitar, pensar", Heidegger nos dice que bauen, cuyo significado es construir, en su origen también es habitar, de ello desprende que construir es propiamente habitar. Más aun, aclara que el término bauen está vinculado al infinitivo del verbo ser -yo soy-, ich bin. Y es por este tipo de relación que: "El habitar es la manera como los mortales son en la tierra" (Heidegger, "Construir, habitar, pensar" 143). Por su parte, los lugares (Orten) se dan a conocer como cosas o construcciones que otorgan espacios, es decir, lo libre (das Frye) y a la vez franqueado (Raum). Fry significa cuidado, preservado de daño y amenaza. Y es este cuidado el rasgo fundamental del habitar. En eso se juega la temporalidad y, a la vez, comprende las ideas propiamente de la arquitectura como son: "planificar, preocuparse, calcular, prever" (Safranski 194).

Este análisis, sin embargo, ha sido cuestionado por el filósofo José Ortega y Gasset. Su convicción proviene del carácter particular del habitar histórico del hombre, el que está relacionado con su adecuación a todas las regiones de la tierra. Y esto lo diferencia de los animales, puesto que ellos habitan en sitios particulares. Para Ortega, este carácter ecuménico o planetaria ubicuidad explica que "la Tierra es para el hombre originariamente inhabitable -unbewohnbar" (Ortega 53). Según este punto de vista, el habitar no le está dado, sino más bien constituye una situación privilegiada y deseada. En su crítica a Heidegger, Ortega argumenta que al interpretar las etimologías, se debe considerar que las palabras no actúan de forma aislada sino formando conjuntos. Las significaciones se obtienen al introducirlas en un contexto, porque señalan una región de la realidad donde están repartidas las cosas. Es decir, precisamente, al modo en el que Heidegger se refiere también a los lugares y a las zonas respectivas, o cuando en Ser y Tiempo se refiere a los útiles con relación a la obra. Heidegger, siempre está mirando 
al conjunto. Diríamos, con esos ejemplos, que el filósofo alemán no razona distinto al español. Pero insiste Ortega:

Muy distinta idea llega a nosotros si ampliamos el horizonte verbal y advertimos que bauen, wohnen y buan no está aislados, sino que la misma raíz aúna las palabras gewinnen -esforzarse por algo-, wunsch-también aspirar a algo que nos falta, que no tenemos todavía-, y wahn. Si consultan ustedes el Kluge-Götze, encontrarán que wahn significa "lo inseguro, lo esperado", así pues, algo que todavía no está ahí; y aún más: “esperanza y esfuerzo", exactamente como gewinnen (Ortega 57-8).

El habitar, analizado desde estas otras etimologías, significa que es algo no alcanzado por el hombre y el esfuerzo que despliega con el construir es la tentativa para conseguir su logro. La Tierra es originariamente inhabitable para el hombre, parece decir Ortega; habitar es un deseo humano. La reflexión del filósofo interpreta más bien el carácter que tendrá el habitar en el período histórico de la modernidad. Hecho que tampoco escapa al filósofo alemán, cuando señala que el habitar aún no ha sido alcanzado por nuestra cultura moderna. Para él, el problema auténtico, la penuria, no es la falta de viviendas, sino el hecho que el hombre, primero "debe aprender a habitar" (Heidegger, "Construir, habitar, pensar 119), porque de lo que se trata es de estar en camino al habitar y el cuidado radica en la instauración de lugares.

\section{El puente instaura el lugar}

Para indicarnos el camino al habitar, en "Construir, habitar, pensar", Heidegger hace la significativa diferencia entre lugar y espacio recurriendo a la descripción del puente de la ciudad de Heidelberg. Con esta evidencia hace una clara distinción entre lo existencial del primero y lo físico del segundo, volviendo a mencionar la diferencia ontológica ya formulada en Ser y Tiempo como algo que requiere ser dilucidado para llegar a comprender qué es el habitar.

El uso habitual que se hace de un puente no tiene las mismas características espaciales de habitar una interioridad. Su carácter transicional, sin embargo, colabora al habitar, instituyendo lugares de encuentro de donde se originan direccionalidades y cercanías. Es decir, el puente reúne en un lugar, en él se despliegan las dimensiones más propias del espacio existencial. Recordemos que los caracteres espaciales que se tratan en Ser y Tiempo, son precisamente la des-alejación (Ent-fernung) y la direccionalidad (Ausrichtung). Según hemos visto en Heidegger, estas dimensiones se corresponden con la espacialidad del dasein, del ser humano cotidiano. En el puente parecen presentarse bajo la figura de la cosa, del útil o del símbolo. Pero, puesto que el puente coliga la cuaternidad (Geviert), es decir, reúne a dioses, mortales, cielo y tierra, no como el espacio puro, el puente mismo puede hacer sitio a una plaza, o a un espacio determinado, que no estaba antes del puente. Coligar para Heidegger es thing, es decir: cosa. Entonces, es por el puente, 
en cuanto cosa, que surge un lugar. Decíamos que el puente no solo reúne la estructura de la cuaternidad al modo de un lugar, también las direccionalidades y se instituye como lugar de encuentro que provoca la cercanía. En su texto De camino al habla (Unterwegs zur Sprache), Heidegger muestra esta capacidad reunidora del lugar a partir de otra de sus acepciones, la palabra de Ort, diciendo:

En su origen lugar $(\mathrm{Ort})$ significa punta de lanza. En ella todo converge hacia la punta. El lugar reúne hacia sí lo supremos como lo extremo. Lo que reúne así penetra y atraviesa todo con su esencia. El lugar, lo reunidor, recoge hacia sí y resguarda lo recogido, pero no como una envoltura encerradora, sino de modo que trasluce y traslumina lo reunido, liberándolo así a su ser propio (Heidegger, De camino al habla 35).

La cuaternidad se constituye con los cuatro elementos congregantes del lugar. Son los que retienen su comprensibilidad, y por ende, su sentido. Históricamente, nos dice Heidegger, los puentes han estado bajo el nombre de un personaje, de un santo, sirven a los mortales para restaurar la continuidad del suelo, congregan una parte de la tierra con su entorno y dejan abovedada la corriente del río, protegida y dirigida al cielo. Del mismo modo como en el puente, también en el habitar converge la cuaternidad. Por lo mismo, "cuidar (mirar por) quiere decir: custodiar la cuaternidad en su esencia” (Heidegger, "Construir, habitar, pensar" 111). Entonces, el carácter esencial del habitar es este cuidado.

Pero, al mismo tiempo, para avanzar en su explicitación de la diferencia entre lugar y espacio, fuerza a este último como a una entidad para colocarlo como medida del lugar buscando así una explicitación de un juego entre ellos e instituir así lo que hemos denominado el espacio-lugar. A diferencia de la idea de espacialidad desplegada en Ser y Tiempo, en donde el espacio es algo que media de modo oculto entre las cosas y el dasein, ahora aflora como una señal, como una negación física que permite decir, aquí se puede hacer espacio al lugar. En este sentido, se activa en tanto vacío que acoge el lugar, como un vacío disponible. En el siguiente párrafo Heidegger despliega la diferencia que hemos señalado insistiendo en la negatividad física del entre, que media o mide los lugares. Escribe el filósofo:

El puente es un lugar. Como tal cosa otorga un espacio en el que están admitidos tierra y cielo, los divinos y los mortales. El espacio otorgado por el puente (al que el puente ha hecho sitio) contiene distintas plazas, más cercanas o más lejanas al puente. Pero estas plazas se dejan ahora como meros sitios entre los cuales hay una distancia medible; una distancia, en griego stadium, es siempre algo a lo que se ha aviado (se ha hecho espacio), y esto por meros emplazamientos. Aquello que los sitios han aviado es un espacio de un determinado tipo. Es, en tanto que distancia, lo que la misma palabra stadion nos dice en latín: un spatium, un espacio entremedio. De este modo, cercanía y lejanía entre hombres y cosas pueden convertirse en meros alejamientos, en distancias del espacio intermedio (Heidegger, "Construir, habitar, pensar” 114-15). 
Al referirse a stadium, stadion y spatium, e interpretarlos como medida, espacio intermedio o mera extensio, Heidegger se refiere a las palabras que designaban los espacios intermedios en sus orígenes. Es decir, se refiere a sitios de acción y movimiento. Así, con la palabra estadio se designa un sitio donde se pasea o corre. En la traducción de Observaciones relativas al arte y El arte y el espacio de Heidegger, Félix Duque entrega su propia versión de estas locuciones y su relación escribiendo:

Spazieren, sí procede (a través del italiano spaziare: "abrirse paso") del latín spatium, un término a su vez emparentado con stádion (eólico spádion). El término griego remite a "fijeza, estabilidad" (misma raíz que hístemi) así que spatium designa algo firme y permanente (gracias a lo cual se puede medir el movimiento: de ahí el estadio como lugar de carreras) (Heidegger, Observaciones relativas al arte - la plástica - el espacio; El arte y el espacio 102).

Con el olvido del sentido constitutivo de los términos, respecto del agente que los activa como lugares, se deriva en que tales espacios pueden ser objeto de abstracción e instituirse a partir de las tres dimensiones, para espaciar cosas y determinar trechos pero en los que no hay lugares del tipo puente o plazas. Tal como se verifica en la arquitectura moderna, los entre han derivado en vacíos vaciados.

Inversamente, son estas cosas, como las construcciones, las que le permiten a Heidegger afirmar que el espacio recibe "su esencia de los lugares y no del espacio" (Heidegger, Observaciones relativas al arte - la plástica - el espacio; El arte y el espacio 114). Esta importante definición parece tomar asidero, aunque las interpretaremos con algunas reservas, en las ideas transmitidas por Aristóteles en el libro IV de la Física. Como sabemos, en este texto se encuentra la doble concepción como tópos y khôra, es decir, de lugar y extensión espacial, las cuales parecen representar, con algunas diferencias, las mismas que hemos venido señalando. En efecto, contrariamente al sentido unitario en que estos conceptos se hallan en el libro del estagirita, estas dos dicciones del espacio parecen ser antagónicas en Heidegger. Especialmente, si recordamos la prioridad ontológica del lugar, reafirmada en el concepto de ort. Y, además, por su crítica a la noción de extensio cartesiana, vertida en el análisis de la espacialidad en Ser y Tiempo. Como sabemos, la extensio remite a la khôra platónica, en la cual Heidegger halla el origen de la noción moderna de espacio (Heidegger, Introducción a la metafísica 100).

Una apostilla a esta observación que señala el sentido de esa doble interpretación en Aristóteles, y que Heidegger elabora de otro modo, la encontramos en el comentario del filósofo Alejandro Vigo a Física IV. La nota comienza por señalar la importancia que tiene para Aristóteles citar Teogonía de Hesíodo, en donde se narra que Caos nació primero que todas las cosas. Escribe Vigo:

En la interpretación de Aristóteles el Caos hesiódico aparece como un vacío existente por sí mismo, que constituye la condición de posibilidad de la existencia de la tierra (Gea) y de todo lo demás. Con la introducción de Caos Hesíodo estaría dando cuenta de la extensión espacial (khôra) en tanto precondición para la existencia de 
los entes, y ello en la convicción de que todo lo existente debe existir en un lugar (Aristóteles 175).

La solución de Vigo reside en que para Aristóteles el espacio constituye prioridad ontológica respecto de los entes que existen en él. Por el contrario, como ya lo hemos dicho, el pensamiento de Heidegger está dirigido hacia la analítica del espacio existencial, con lo cual no duda en dar prioridad al tópos como lugar, como dimensión espacio-temporal en donde se da el trato cotidiano y habitual. No así la khôra, pues la comprende sucintamente, como "el espacio determinado por la extensión" (Heidegger, Introducción a la metafísica 101).

Para Félix Duque, en sus notas a Observaciones relativas al arte y El arte y el espacio de Heidegger, Khôra y Cháos (caos) se encuentran en su origen etimológico como lo abierto, y por ello es lo que "mantiene la distancia entre los entes" (Heidegger 101). Avanza así, el filósofo, en la constitución de una idea de lugar que desea contrastar netamente del espacio pero que, sin embargo, según nuestra lectura, en forma contraria aunque paulatina va conformando una vía de acceso a la espacialidad existencial por medio del espacio-lugar, cuya manifestación abre la posibilidad de aviar el espacio, es decir, de algo que puede presentarse pero ya no como matriz. Heidegger en "Construir, habitar, pensar", señala:

Las cosas que son lugares de este modo, y solo ellas, otorgan cada vez espacios. Lo que esta palabra Raum (espacio) nombra lo dice su viejo significado: raum, rum que quiere decir lugar franqueado para la población y campamento. [...] Un espacio es algo aviado (espaciado), algo a lo que se le ha franqueado espacio, o sea dentro de una frontera, en griego $\pi \varepsilon \dot{\varepsilon} \rho \varsigma$. La frontera no es aquello en lo que termina algo, sino, como sabían ya los griegos, aquello a partir de donde algo comienza a ser lo que es (comienza su esencia). [...] Espacio es esencialmente lo aviado (aquello a lo que se ha hecho espacio), lo que se ha dejado entrar en sus fronteras. Lo espaciado es cada vez otorgado, y de este modo ensamblado, es decir, coligado por medio de un lugar, es decir, por una cosa del tipo del puente. De ahí que los espacios reciban su esencia desde lugares y no desde "el" espacio" (114).

Por consiguiente, solo atribuyendo a los lugares el carácter de cosa se otorga espacio, lo libre y a la vez franqueado (Raum). Entonces, ¿cuál es la relación entre hombre y espacio?, pregunta el filósofo. Afirma que ellos no se contraponen, pero la relación pertenece a la esencia del pensar, es decir, en este caso, a estar ya en un determinado lugar. En esa estrecha relación surge el espacio.

Estas reflexiones son fundamentales para comprender el paso que hace el filósofo en Ser y Tiempo entre la relación espacial de dasein y las cosas y aquella entre el hombre y el habitar, como fundamento existencial del texto de la conferencia que analizamos. Para Heidegger: "Los espacios se abren por el hecho que se los deja entrar en el habitar de los hombres. Los mortales son; esto quiere decir: habitando aguantan espacios sobre el fundamento de su residencia cabe cosas y lugares" (116). 
Si un propósito de este trabajo es el de sostener la idea de lugar como algo difícil de escindir del espacio, ahora se vuelve necesario poner en juego el alcance de las afirmaciones de Heidegger, en el caso particular elegido: la cabaña en Todtnauberg. Puesto que las tentativas heideggerianas han manifestado claramente su opción por la dimensión existencial, surge la pregunta sobre cómo relacionar esa dimensión con las características físicas del espacio implicadas en la construcción. Corresponde preguntar cómo el espacio físico también es algo presente o que puede aparecer en la experiencia cotidiana, tal como sugiere la khôra, por su condición de matriz o libre apertura para acoger lugares. Buscando dilucidar este punto recurriremos a esa construcción y a los vínculos con su entorno, para intentar comprender la modalidad en la cual Heidegger concibe el espacio y su constitución.

\section{La estrechez de la cabaña}

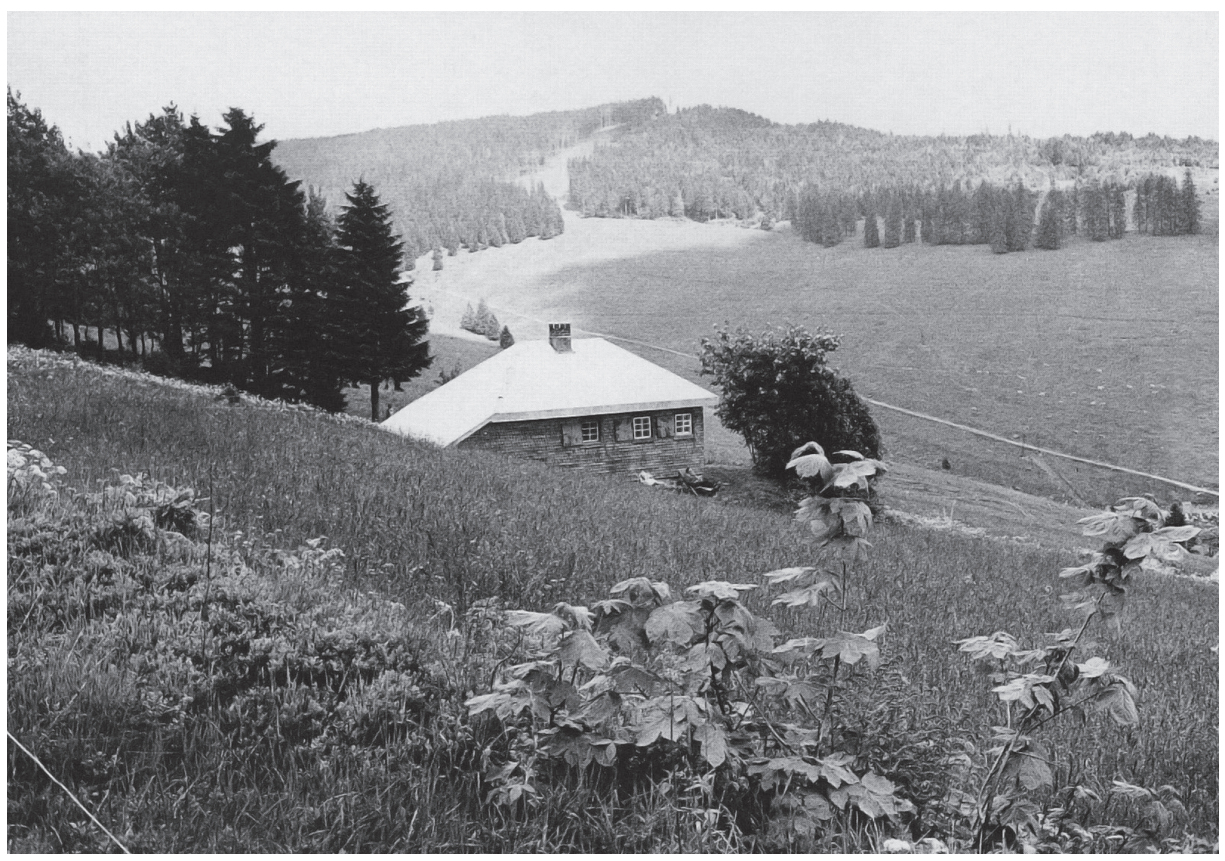

Imagen 1. La cabaña en la Selva Negra en 1968. Fotografía de Digne Meller-Marcovicz (Sharr, Heidegger’s Hut 43).

Desde el verano de 1922, y por cerca de cinco décadas, Heidegger ocupó una pequeña cabaña de esquí de solo 42 metros cuadrados. Ubicada en la cercanía del pequeño pueblo de Todtnauberg, en medio de la Selva Negra (Schwarzwald), nombre de una masa boscosa de montaña localizada en el sur de Alemania, esta construcción de madera fue su lugar 
de trabajo y, aventuramos, fuente de reflexión permanente. En efecto, la mayoría de sus trabajos fueron pensados y escritos en esa especie de embarcación anclada en los verdes faldeos. La llamaba die Hütte, y entre las estrechas habitaciones y el abierto entorno, el filósofo halló su lugar propio.

Más aun, pareciera que en la relación de familiaridad que ofrece esta pequeña cabaña está el origen de algunos de los conceptos que Heidegger elabora para tratar el tema del espacio existencial. Por ejemplo, con el concepto de Zuhandenheit, tratado en Ser y Tiempo, que vincula las cosas y útiles mediante el uso en una relación de cercanía. De este trato en la cotidianidad, que el mismo filósofo desarrolla como habitante, nace su indicación esencial: tomar los fenómenos tal como se manifiestan y no a partir de elucubraciones abstractas o de dogmas.

Heidegger nombra la cabaña según su ubicación respecto de la montaña. Decía, allá arriba (oben), con relación a la ciudad que está mil metros por debajo o allá abajo (unten) si se encontraba en la altura de la colina; una nominación básica de los lugares, tal como se escucha en el lenguaje cotidiano. Pero arriba no es una mera dirección espacial, es también la experiencia de estar ligado al aire libre con el cuerpo como evidencia, por el esfuerzo del traslado. El abajo implica la gravedad de la tierra y el movimiento que nos arrastra con ligereza. Las palabras son primordiales para identificar el lugar, remiten a los diversos sentidos espaciales y corporales de las cosas y sus potenciales movimientos, cuyo resultado natural señala el sitio que les corresponde en la naturaleza, al buscar su lugar más propio. Para Aristóteles:

[...] las traslaciones de los cuerpos físicos simples como fuego, tierra y semejantes, ponen de manifiesto que el lugar no es solo algo existente, sino también que posee cierta potencia. En efecto, de no haber impedimento, se traslada cada uno de ellos a su lugar propio: lo uno hacia arriba, lo otro hacia abajo. Éstas son partes o especies de lugar, es decir, “arriba”, “abajo”, y el resto de las seis dimensiones (208b 10).

Habitar la cabaña para el filósofo es más que poseer un alojamiento, es estar en el lugar al que se pertenece. Allí es y está en consonancia con el entorno. Está en casa, haciéndose parte de las fuerzas naturales que se desatan con energía en la densidad del bosque. Por ello, él mismo comprende su trabajo y su producción intelectual, su pensar, como algo tangible, como aquel que realiza la naturaleza que lo rodea, árboles y montañas que, además, le recuerdan el trabajo de los campesinos. Tal como Sharr relata en su libro sobre la cabaña del filósofo:

Es solo el trabajo el que nos abre un espacio para la realidad que son estas montañas. El curso del trabajo queda incrustado en lo que sucede en esta región. [...] La lucha para moldear algo en lenguaje es como la resistencia de los altos abetos contra la tormenta. [...] Y este trabajo filosófico no discurre como los lejanos estudios sobre algo excéntrico. Permanece justamente en medio del trabajo de los campesinos (66). 
Esta esfera de manifestación del espacio-lugar se ajusta a la necesidad vital del ser humano por dar cuenta de su pertenencia a un lugar y se estructura en diversos niveles de relaciones existenciales; mentales, emocionales y físicas, como el filósofo muestra y analiza en Ser y Tiempo. Su convencimiento es que el ser humano actúa, observa o experimenta porque se encuentra en un mundo. Las relaciones antes mencionadas son experimentadas en el ámbito rural; allí las dimensiones del quehacer cotidiano y la propia estructura de la cabaña remiten a una experiencia espacio-temporal que abre un sentido particular en el que la vida toma lugar. Al parecer, Heidegger no experimenta este fenómeno con el mismo interés en la ciudad, esta se le presenta con rasgos más propios de la inautenticidad y del desarraigo. En 1934 publica un artículo de prensa en el que afirma su voluntad de permanecer en el entorno campestre, cuyo título es "Paisaje creador: ¿por qué permanecemos en la provincia?".

Lo que se abre en esos parajes boscosos, remiten a una condición primigenia del habitar en donde la existencia está en disputa con la naturaleza². Tal como se expresa en la frase "la resistencia de los altos abetos contra la tormenta", la cabaña también opone una mundanizada tenacidad que busca sortear las inclemencias de los elementos. La condición severa de las fuerzas naturales de esas latitudes transporta a la condición primigenia, desprotegida, del hombre frente a la naturaleza, así como la han narrado los pensadores presocráticos.

Según observa Rüdiger Safranski, en ocasiones, cuando la cabaña era objeto de visita por parte de algunos de sus estudiantes, Heidegger, buscando recrear ese clima original encendía unos leños delante de la cabaña y hacía un discurso. En cierta ocasión, comenta Safranski, comenzó su oración diciendo: “Estar despierto en el fuego de la noche' [...] y en la próxima frase estaba de nuevo con sus queridos griegos. Parménides hacía acto de presencia en Todtnauberg" (165).

La cabaña es la casa, el lugar del cuidado del hombre. Luego, a través de esta experiencia, Heidegger podrá concebir su idea del lenguaje (la casa) en tanto cuidado del ser. En su Carta sobre el Humanismo escribe:

[...] destinalmente la esencia del hombre en su morar en la verdad del ser. Este morar es la esencia del ser-en-el-mundo [...] La referencia que allí se hace al «ser-en» en cuanto «morar» está lejos de ser un juego etimológico. La referencia en la conferencia de 1936 al verso de Hölderlin «Lleno de mérito, mas poéticamente mora / el hombre sobre la tierra» no es ningún adorno de un pensar que se salva de la ciencia refugiándose en la poesía. Todo este hablar sobre la casa del ser no es ninguna transposición de la imagen de la "casa» al ser. Lo que ocurre es que, partiendo de la esencia del ser, pensada del modo adecuado y conforme a su asunto, un día podremos pensar mejor qué sea «casa»y qué «morar» $(81)$.

2 Nos referimos a la idea de lucha entre tierra y mundo como señala Heidegger en el ensayo "El origen de la obra de arte", refiriéndose a la relación entre templo y entorno. 
Las motivaciones, necesidades y deseos relativos a la constitución del habitar y su relación con las cosas, suponen la casa y con ella la inscripción de las acciones cotidianas en el espacio, lo cual deriva en la definición de lugares. En la referencia que Heidegger hace al útil en Ser y Tiempo, señala el sentido que este adquiere en el trato cotidiano: un sentido pragmático que parece originarse en la observación del modo en el que ocurre la interacción en la experiencia espacial de la cabaña. La condición de aislamiento de esta última, la falta de equipamientos modernos y la estrechez interior de la envolvente material-que define los límites espaciales-promueve la manipulación de útiles e implementos sugiriendo una circularidad en el uso y la pertinencia a unos lugares precisos. La prioridad de las tareas cotidianas, los para algo de la obra están vinculados a los utensilios cercanos y a la mirada que posibilita el acceso. Escribe Heidegger en Ser y Tiempo:

De acuerdo a su pragmaticidad, un útil solo es desde su pertenencia a otros útiles; útil para escribir, pluma, tinta, papel, carpeta, mesa, lámpara, muebles, ventanas, cuarto. Esas "cosas" no se muestran jamás por separado, para llenar luego un cuarto como suma de cosas reales. Lo inmediatamente compareciente, aunque no temáticamente captado, es el cuarto, que, por su parte, no es lo que se halla "entre las cuatro paredes" en un sentido geométrico espacial, sino un útil-habitacional (96).

En esta cita, no solo hay relaciones de involucramiento y pertinencia entre las cosas en la vida cotidiana, sino que también se pueden inferir de ella sugerencias con respecto al espacio. Las cosas se relacionan a la espacialidad aunque no entendamos el cuarto como algo físico, sino como lo inmediatamente compareciente. De igual modo deja entrever el juego posible de relaciones espaciales sucesivas y graduales que pueden generarse con otros cuartos igualmente necesarios respecto de una determinada tarea que los involucre. Experimentar este juego de espacialidades comprendidas unas con otras, es un modo en el cual comparece el espacio, esto significa mostrar lo propio del fenómeno, es decir, como "el enunciarse de algo que no se muestra, por medio de lo que se muestra" (Heidegger, Ser y Tiempo 52). Sin embargo, la experiencia no remite solo a la relación entre las cosas y el útil-habitacional en el espacio interior, también a las condiciones de habitabilidad que están pensadas para hacer frente al rigor de los elementos naturales, como temporales y nevazones. Entonces, tanto una luz interior tenue como las condiciones que imponen las bajas temperaturas durante la mayor parte del año evocan una espacialidad atmosférica y nostálgica.

\section{Apertura hacia la vastedad de la comarca}

En Hombre y espacio (1969), el filósofo Otto Friedrich Bollnow señala que el término espacio en alemán: Raum aparece prioritariamente con el significado de habitación, recinto o pieza, como parte de la casa que sirve para diversas finalidades, es decir, como unidad que compone la vivienda, acepción cercana a la idea de cuarto de la que se hablaba con 
anterioridad, ${ }^{3}$ reafirmando Raum como la idea de un útil, hueco y aislado, disponible y no ocupado por otra cosa. Por otra parte, habla de Platz (sitio) y de Ort (lugar), refiriéndose a lo exterior. Genéricamente, espacio también es Spielraum, aquello que permite la libertad para ejecutar un movimiento y Zwischenraum: espacio intermedio (Bollnow 38). Estas indicaciones sobre el concepto refieren inequívocamente a una concepción vinculada a la potencialidad del espacio en la vida concreta. Ello se confirma con una ulterior significación de la palabra, ya vista en Heidegger, que Bollnow desarrolla aseverando que el espacio no sería algo dado, sino que se constituye gracias a los actos humanos. En este sentido de la palabra, el espacio se crea haciendo vacío, despejando. Bollnow, al examinar el diccionario alemán Grimm y el diccionario etimológico de Kluge-Götze escribe:

Así, el Grimmsche Wörterbusch dice de la significación primitiva de la palabra räumen ("evacuar, desocupar, despejar"): "crear un espacio, un claro en el bosque con el propósito de la roturación o de la colonización”. De ahí viene determinado el sustantivo Raum. Según Grimm, los diversos documentos comprobantes antiguos califican la palabra Raum de "término antiquísimo de los colonos [...] que designa en primer lugar la acción de roturar y de despejar una selva para fundar un lugar de establecimiento [...] y finalmente la colonia misma así obtenida”. Estas indicaciones son muy significativas. Sabemos por el léxico de Kluge-Götze que, en este mismo sentido, se formó a partir de un adjetivo de la lengua germánica común en el sentido de "vasto" (geräumig) y que sus tempranas derivaciones equivalían a "sitio libre, campamento, asiento, cama". En una significación ya más amplia, el espacio designa aquí un espacio hueco que recibe, protector, al hombre, en el que éste puede moverse libremente, y que es separado de un algo que le rodea que ya no es calificado de espacio. Cierto sentimiento de protección parece vibrar en todo ello (40).

El espacio, si bien es algo despejado, también es aquello que está entre las cosas. Los objetos dejan más o menos espacio, puede ser estrecho o vasto, pero debe estar libre, disponible para el movimiento o la ocupación. Cuando ello no ocurre se habla de falta de espacio y dicha falta resuena en el sujeto como algo que le oprime. Bollnow interpreta la vastedad como " $[. .$.$] apertura de un campo para el movimiento, en que nada se opone al$ afán humano de expansión, a su avance conquistador en el espacio” (88).

\section{Epílogo}

Cuando Heidegger deja la interioridad de la cabaña se mueve por senderos y claros de luz entre la masa boscosa, y se encuentra con las aberturas que dejan entre ellas las cabañas cercanas, con los intersticios y senderos entre colina y colina. Heidegger en sus paseos

3 Bollnow señala también las locuciones Wohnräume (cuarto de estar) y Nebenräumen (cuartos contiguos). 
reflexiona: "Este es mi mundo de trabajo [...] Hablando con rigor, nunca contemplo el paisaje" (Heidegger, "Construir, habitar, pensar" 116). Los senderos de travesía, paseos y de esquí que conducen o alejan la cabaña, su lugar, espacian el espacio. Y solo por la relación con la interioridad de la cabaña se constituye lo abierto. El sendero provee la libertad de movimiento para la constitución del espacio mismo, así como vimos el rol que juega el espacio al modo de los cuartos ensamblados para desplegar una totalidad. Por medio de sus paseos aparecen lugares de encuentro desde los cuales se miden existencialmente distancias, direcciones y traspasos: "Y solo porque los mortales, conforme a su esencia, aguantan espacios pueden atravesar espacios" (Heidegger, "Construir, habitar, pensar" 116). El desplazamiento por el bosque despeja, libera para hacer espacio. $Y$ en este hacer espacio, el espacio espacia (der Raum räumt), ello proviene del carácter puntual y unitivo de la cabaña en tanto lugar (Ort) y el acto de moverse hacia fuera del recinto íntimo y la extensión hacia la comarca (Gegend). En el hecho de recorrer y estar orientado hacia la exterioridad misma es donde el espacio acontece. Este movimiento por caminos o sendas no solo define el ritmo de las acciones complementarias con aquellas del interior de la cabaña, propias de la cotidianeidad, sino que en virtud de la experiencia de recorrer el espacio (spaziergang), se espacia el espacio.

Supusimos que en esta acción cotidiana parece estar cifrado algo esencial para comprender lo propio del espacio. Según nos ha conducido este autor, desde el espacio existencial del dasein a la espacialidad del espacio, creemos haber comprendido que son los lugares mismos los que muestran el espacio, que los lugares o construcciones del tipo puente acogen la promesa de un habitar, y que la tarea de la arquitectura es configurar el juego del espacio-lugar donde la existencia pueda darse.

\section{Referencias}

Aristóteles. Física. Libros III - IV. Trad., introducción y comentarios Alejandro Vigo. Buenos Aires: Biblos, 1995. Medio impreso.

Bollnow, Otto Friedrich. Hombre y espacio. Barcelona: Labor, S. A., 1969. Medio impreso. Heidegger, Martin. Ser y Tiempo. Santiago de Chile: Universitaria, 2005. Medio impreso. ---. Carta sobre el Humanismo. Madrid: Alianza, 2004. Medio impreso.

---. Observaciones relativas al arte- la plástica - el espacio; El arte y el espacio. Introducción y notas de Félix Duque. Navarra: Cuadernos de la Cátedra Jorge Oteíza. Universidad Pública de Navarra, 2002. Medio impreso.

---. “Construir, habitar, pensar”. Conferencias y artículos. Barcelona: Del Serbal, 2001. 109-119. Medio impreso.

---. De camino al habla. Barcelona: Del Serbal, 1987. Medio impreso.

Ortega y Gasset, José. Pasado y porvenir para el hombre actual. Madrid: Revista de Occidente, 1962. Medio impreso. 
Petzet, Heinrich Wiegand. Encuentros y diálogos con Martin Heidegger 1929-1976. Buenos Aires: Katz, 2007. Medio impreso.

Safranski, Rüdiger. Un maestro de Alemania. Martin Heidegger y su tiempo. Barcelona: Tusquets, 2007. Medio impreso.

Sharr, Adam. Heidegger's Hut. Massachusetts: The MIT Press, 2006. Medio impreso. ---. Heidegger for architects. Abingdon: Routledge, 2007. Medio impreso. 